\section{Annual General Meeting: Executive Board Report}
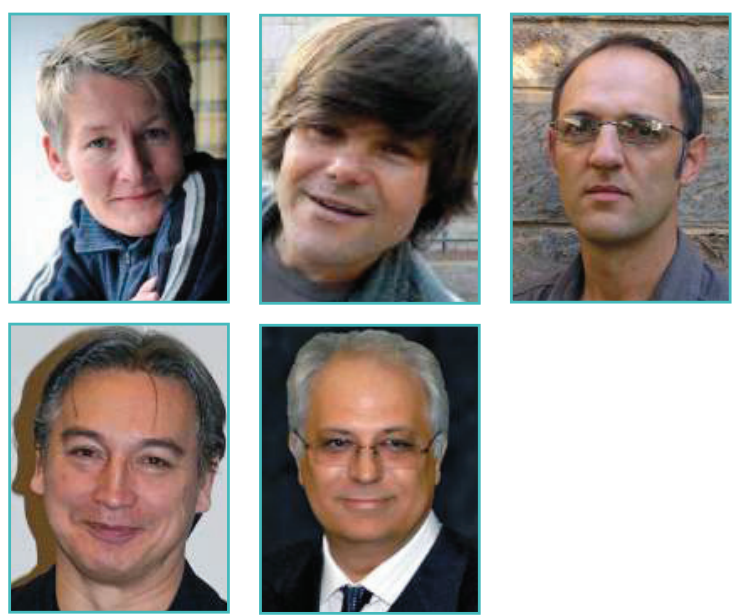

Teresa K Attwood', Andreas Gisel2, Etienne de Villiers ${ }^{3}$, Erik Bongcam-Rudloff ${ }^{4}$, Goran Neshich ${ }^{5}$

'The University of Manchester, Manchester, United Kingdom 2Institute for Biomedical Technologies, CNR, Bari, Italy ${ }^{3}$ Kenya Medical Research Institute (KEMRI), Kenya ${ }^{4}$ Department of Animal Breeding \& Genetics, Swedish University of Agricultural Sciences, Uppsala ${ }^{5}$ EMBRAPA, Brazil

Received 18 June 2013; Published 19 August 2013

During the past year, the Executive Board (EB) met regularly and held frequent meetings with the Operational Board via Skype. These meetings allowed discussion of a range of issues relating to the Project Committees (PCs), to EMBnet.journal, to the website, the Stichting accounts, membership, etc.

In alternate months, we also endeavoured to convene Skype meetings open to the full EMBnet constituency; however, for larger numbers of attendees, technical issues continued to cause problems. Attempting to address these issues, we took the first steps towards evaluating the various tools and technologies available for online meetings, by creating a list of existing tools, and a protocol on how to test them. The test will be realised in the same spirit as the 'ping project' ' of the '80s. The 2013 AGM allowed us to convene a working group to discuss the issues in more detail, and to initiate a common experiment with different software and different Nodes. The ultimate goal is to

1 en.wikipedia.org/wiki/Ping \%28networking utility\%29 write a white paper and to publish the results in EMBnet:journal.

The last year has been both busy and productive, building substantially on the programme of work we outlined in 2010. In particular, working closely with Itico $^{2}$ to improve the EMBnet 'brand', we finally launched the new website, which now includes a new online fee-payment module for individual members. We call on all members to help augment the content of the new site and to help keep it up-to-date.

Since the 2012 AGM in Uppsala, EMBnet's training strategy has been dominated by our leadership of $\mathrm{GOBLET}^{3}$ (the Global Organisation for Bioinformatics Learning, Education and Training), which has been established as a Stichting, registered in the Netherlands, following the successful model of EMBnet. Working through GOBLET has significantly increased our level of interaction and cooperation with a range of major international societies and networks (including $\underline{I S C B}^{4}$, $\underline{\mathrm{ASBCB}^{5}}, \mathrm{ISB}^{6}, \mathrm{APBiONet}^{7}$, SolBio ${ }^{8}, \underline{A B N}^{9}$ and so on) - from the original 10 members who signed the Memorandum of Understanding to establish GOBLET, a further 16 organisations and several individuals have committed to join the Foundation.

Another profound advance for EMBnet this year has been the final ratification of the new statutes, which were voted in during the Uppsala 2012 AGM - these statutes became legally binding in April 2013. The most significant result of the change is that we are now able formally to accept individual members (this allows, say, former Node managers to join, or any individual to participate in EMBnet's activities but whose organisation is not a member). Since ratification of the statutes, we have already had several membership applications, and welcomed one new organisation; new memberships will be processed without delay via the online payment system. The new statutes also ushered in changes to the internal structure of the organisation, obliging the PC Chairs and the EB to work together much more closely than they have done in the past; it has also allowed us to streamline the way in which EMBnet's activities

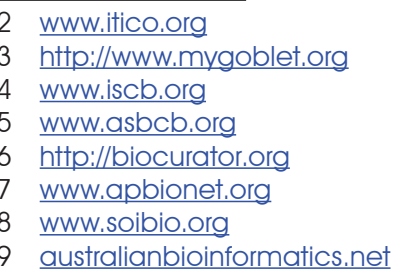


are coordinated, no longer requiring Committee members to be elected but rather, giving the PC Chairs greater flexibility to interact with members who most want to contribute to their work.

During the year, we have continued to work closely with other EU-funded projects, such as AllBio and SeqAhead. AllBio ${ }^{10}$ had its first AGM in Amsterdam (December 2012), where plans for the project's second year were discussed, including the all-important, 'Bioinformatics Workshop: Evaluation of Test Cases ${ }^{11}$. Authors of selected test cases and specific bioinformatics specialists were invited to this event, hosted in Milan by EMBnet Italy ( ${\underline{C N R}-I_{B}{ }^{12}}^{2}$. During the three-day workshop, various round-table discussions were held, and several new events were devised to help provide test-case solutions. Two of these 'hackathons' have already happened: one hosted in Amsterdam by EMBnet Netherlands $\left(\mathrm{CMB}^{13}\right)$ (March 2013); one hosted in Bari by EMBnet Italy (April 2013). In this second year, EBI ${ }^{14}$ (EMBnet UK) organised two AllBio-sponsored courses: one on analysis of genome-scale data from plant pathogenic fungi (PhytoPath), the other on data resources and tools for 'plant-omics'. A further key AllBio event took place in Munich (October 2012) - the 'AllBio Ontology Workshop: Using Biomedical Ontologies for Improved Bioinformatics Database Interoperability', organised by EMBnet UK (UMBER ${ }^{15}$ ) and EMBnet Netherlands. A full list of AllBio events is available from www. allbioinformatics.eu/doku. php?id=public:events.

Within SeqAhead ${ }^{16}$, EMBnet Nodes were involved in several events covering different problems in NGS data analysis. In chronological order, EMBnet Sweden $\left(\mathrm{BMC}^{17}\right)$ and EMBnet Netherlands (CMBI) organised the 'Irans-COST Bioinformatics ${ }^{18}$, event in Amsterdam; and EMBnet Italy (CNR-ITB) was involved in the COST Workshop 'The next NGS Challenge: High-throughput omics and Data Integration ${ }^{19}$, in Barcelona, and organised the COST Workshop 'NGS and non-coding RNA data analysis ${ }^{20}$, in Bari. Three further events are worthy of note: in May, the COST conference 'The Next NGS Challenge: Data Processing and Integration ${ }^{21}$, in Valencia, involving EMBnet Sweden (BMC), EMBnet Italy (CNR-ITB) and EMBnet Spain $^{22}$ (CSIC); in June, a 'Hadoop and NGS data processing' hackathon ${ }^{23}$, hosted in Sardinia by EMBnet Finland $\left(\mathrm{CSC}^{24}\right)$, and a COST Workshop on 'Future demands and challenges in ICT and bioinformatics tools for NGS', with EMBnet Finland (CSC), EMBnet Sweden (BMC) and EMBnet Italy (CNR-ITB).

Throughout the year, we have described these and our other activities in our monthly EMBnet.digest $^{25}$ and in EMBnet.journal ${ }^{26}$. During 2012, the bulk of the journal work has involved preparation of conference proceedings for the BITS 9th Annual Meeting (see EMBnet.journal 18 Suppl. $A^{27}$ ) and NETTAB 2012 (see EMBnet.journal 18 Suppl. ${ }^{28}$ ).

This year's AGM was an opportunity to strategically re-group in order to build on some of these initiatives, and to prioritise new projects and proposals to attract more funding. This year, one member of the EB (Erik Bongcam-Rudloff) was up for re-election, and was duly re-elected. As always, there's still a lot more work to do. We therefore encourage you all to contribute your energies and visions to EMBnet, both to make this 25th Anniversary year of EMBnet a real celebration and to prepare the way for the next 25 years of the Global Bioinformatics Network!

Chair: T.K. Attwood

Secretary: A.Gisel; Treasurer: E. de Villiers; Members: E. Bongcam-Rudloff, G. Neshich

\footnotetext{
10 www.allbioinformatics.eu

11 http://www.allbioinformatics.eu

12 www.embnet.org/nodes/institute-biomedical-technologies-itb

13 www.embnet.org/nodes/centre-molecular-and-biomolecular-informatics-cmbi

14 www.embnet.org/nodes/embl-outstation-europeanbioinformatics-institute-embl-ebi

15 www.embnet.org/nodes/university-manchester-umber

16 www.segahead.eu

17 www.embnet.org/nodes/biomedical-centre-bmc

18 http://seqahead.cs.tu-dortmund.de/meetings:trans$\underline{\text { cost }}$
}

19 www.segahead. it/cost-bcn-2013

20 http://www.segahead. it/cost-bari-2013/www.thenextngschallenge.org

21 www.thenextngschallenge.org

22 www.embnet.org/nodes/centro-nacional-de-biotecnología-csic

23 www.crs4.it/news/-/blogs/hadoop-and-ngs-data-processing-hackathon-iii

24 www.embnet.org/nodes/csc-scientific-computing-ltd

25 www.embnet.org/embnet-digest

26 http://journal.embnet.org

27 journal.embnet.org/index.php/embnetjournal/issue/ view/61

28 journal.embnet.org/index.php/embnetjournal/issue/ view/73 